\title{
Hazards of Hindsight - Monitoring the Safety of Nutritional Supplements
}

\section{Citation}

Cohen, Pieter A. 2014. "Hazards of Hindsight - Monitoring the Safety of Nutritional

Supplements." New England Journal of Medicine 370 (14) (April 3): 1277-1280. doi:10.1056/ nejmp1315559.

\section{Published Version}

10.1056/NEJMp1315559

\section{Permanent link}

http://nrs.harvard.edu/urn-3:HUL.InstRepos:34854268

\section{Terms of Use}

This article was downloaded from Harvard University's DASH repository, and is made available under the terms and conditions applicable to Other Posted Material, as set forth at http:// nrs.harvard.edu/urn-3:HUL.InstRepos:dash.current.terms-of-use\#LAA

\section{Share Your Story}

The Harvard community has made this article openly available.

Please share how this access benefits you. Submit a story.

Accessibility 

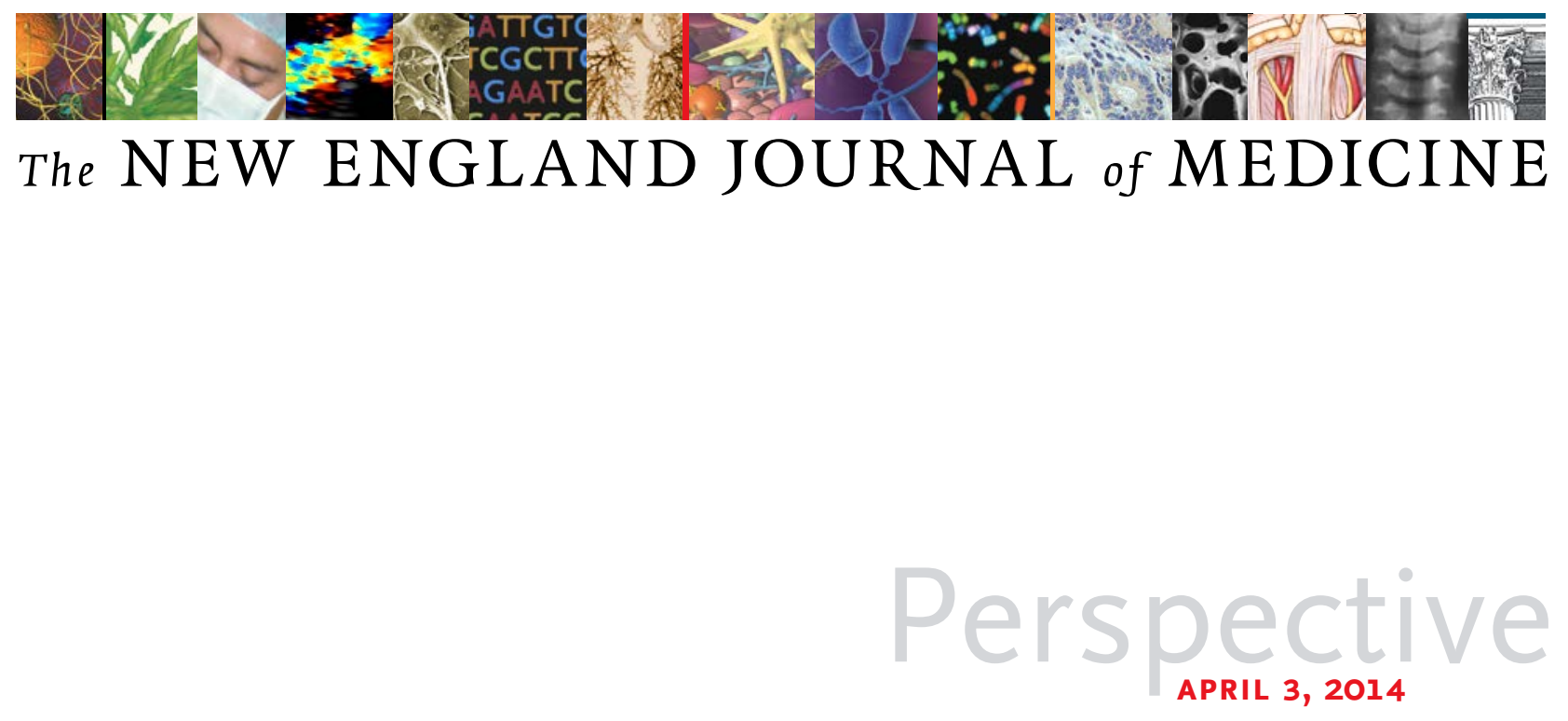

\section{Hazards of Hindsight - Monitoring the Safety of Nutritional Supplements}

Pieter A. Cohen, M.D.

\section{- pidemiologists at the Centers for Disease Con- Ctrol and Prevention (CDC) recently confirmed what an astute liver-transplant surgeon in Honolulu already suspected: OxyElite Pro, a popular over-the-}

counter supplement, was responsible for a cluster of cases of severe hepatitis and liver failure. ${ }^{1} \mathrm{Al}-$ though patients began to develop severe hepatitis in May 2013, the Food and Drug Administration (FDA), whose job it is to remove dangerous supplements from store shelves, did not learn of the cases until mid-September, 4 months later. By February 2014, the FDA had linked 97 cases, resulting in 47 hospitalizations, three liver transplantations, and one death, to OxyElite Pro. This dietary supplement was recalled, but nothing has been done to prevent another supplement from causing organ failure or death. Nor have any changes been made to improve the FDA's ability to detect dangerous supplements.

The FDA's delayed response - with its life-threatening consequences - is attributable to our woefully inadequate system for monitoring supplement safety. Americans spend more than $\$ 32$ billion a year on more than 85,000 different combinations of vitamins, minerals, botanicals, amino acids, probiotics, and other supplement ingredients. Unlike prescription medications, supplements do not require premarketing approval before they reach store shelves. Under the Dietary Supplement Health and Education Act of 1994, anything labeled as a dietary supplement is assumed to be safe until proven otherwise. The FDA is charged with the unenviable task of identifying and removing dangerous supplements only after they have caused harm.

And the agency has its work cut out for it: potentially dangerous supplements are widely available. More than 500 supplements have already been found to be adulterated with pharmaceuticals or pharmaceutical analogues, including new stimulants, novel anabolic steroids, unapproved antidepressants, banned weight-loss medications, and untested sildenafil analogues. ${ }^{2}$ In 2013 alone, researchers discovered two new stimulants in widely marketed supplements. My colleagues and I identified a new analogue of methamphetamine, $\mathrm{N}, \alpha$-diethylphenylethylamine ( $N, \alpha$-DEPEA), in a popular sports supplement. ${ }^{3}$ FDA scientists discovered another stimulant, $\beta$-methylphenethyla- 
mine $(\beta$-MePEA) - a novel analogue of amphetamine - in nine supplements. ${ }^{4} \quad \mathrm{~N}, \alpha$-DEPEA and $\beta$-MePEA have never been studied in humans, and their adverse effects are entirely unknown; yet they are sold as "natural" products without having undergone any premarketing testing for safety. the CDC, or the Department of Defense have often been the first to detect harm from supplements. The recent cluster of patients with liver failure in Hawaii is a case in point: MedWatch reports were submitted only after the local department of public health was already investigating

\section{Sweeping changes would be needed to create an effective surveillance system capable of rapidly detecting supplement-related adverse events in the United States.}

(Although supplements containing $N, \alpha$-DEPEA were voluntarily withdrawn from the market, supplements containing $\beta$-MePEA remain widely available.)

Rapid detection of harm from these and other supplements is essential to minimizing risks to consumers. The FDA currently relies on MedWatch (https://www .safetyreporting.hhs.gov), the FDA's online portal for clinicians to voluntarily report adverse events associated with prescription drugs, medical devices, or dietary supplements. MedWatch suffers from significant underreporting and incomplete reports, which hamper its ability to detect harms even from prescription medications. It is even less effective in detecting adverse effects of supplements, a more complicated task because supplements are sold directly to consumers, often contain multiple active ingredients, and are too often inaccurately labeled.

MedWatch reports have rarely provided sufficient and adequately timely data to permit detection of clusters of serious adverse effects from supplements. Instead, local public health departments, supplement use among affected patients. Similarly, in 2008, when a poorly manufactured multivitamin was responsible for more than 200 cases of selenium poisoning - with symptoms including diarrhea, fatigue, hair loss, and joint pain - local health departments cracked the case linking the illness to the multivitamin; MedWatch reports were irrelevant. More recently, in 2011, the Department of Defense removed supplements containing the stimulant 1,3-dimethylamylamine (DMAA) from military bases because of safety concerns. It took the FDA an additional 16 months after the military ban to gather sufficient safety data from MedWatch to alert consumers about DMAA's risks. Despite a concerted effort by the FDA to remove the stimulant, DMAA remains in dozens of supplements. During the 2014 Winter Olympics, three Olympians were banned for using DMAA - all three reported inadvertently consuming it in supplements.

MedWatch also lacks the capacity to provide clinical advice to providers caring for affected patients. Clinicians are often unfamiliar with supplement ingredi- ents and may turn to poison centers, which offer free medical advice after any type of poison exposure. An investigation by the Government Accountability Office revealed that between 2008 and 2010, more than 1000 supplementrelated adverse events were reported to poison centers but not reported to the FDA. Because data are not routinely shared between the centers and the agency, the FDA did not have access to any of these reports.

What can be done? A bill currently being reviewed by committee, the Dietary Supplement Labeling Act, sponsored by Senators Dick Durbin (D-IL) and Richard Blumenthal (D-CT), would require supplement manufacturers to register their products with the FDA and to provide more safety information, such as information about known adverse effects, to consumers (see table). The bill is a step toward ensuring that vitamins, minerals, botanicals, probiotics, and other supplement ingredients are accurately labeled, but it would not improve the FDA's ability to detect and remove dangerous supplements from store shelves.

Sweeping changes would be needed to create an effective surveillance system capable of rapidly detecting supplement-related adverse events in the United States. I believe that accurate information on every supplement sold in this country should be incorporated into databases maintained by both the FDA and poison centers. Appropriate public health responses would be expedited if all key organizations, including the poison centers, the Defense Department, local departments of public health, and manufacturers, shared reports of serious supplement-related adverse 
Examples of Potential Adverse Reactions to Legal Ingredients and Adulterants in Dietary Supplements.*

\begin{tabular}{|c|c|}
\hline Symptoms and Syndromes & Examples of Potentially Responsible Supplement Ingredients \\
\hline Arrhythmias & $\begin{array}{l}\text { Ephedra (ephedra species), horny goat weed (epimedium species), oleander } \\
\text { (Nerium oleander), stimulants } †\end{array}$ \\
\hline Bleeding & Ginkgo (Ginkgo biloba), NSAIDs \\
\hline Cancer & $\begin{array}{l}\text { Anabolic steroids (linked to hepatoma), beta-carotene (lung cancer), vitamin E } \\
\text { (prostate cancer) }\end{array}$ \\
\hline Gynecomastia, acne, hirsutism, infertility & Anabolic steroids and precursors (e.g., high-dose androstenedione and DHEA) \\
\hline Hepatotoxic effects & $\begin{array}{l}\text { Aegeline, anabolic steroids, chaparral (larrea species), comfrey (Symphytum offici- } \\
\text { nale), fo-ti (Polygonum multiflorum), germander (Teucrium chamaedrys), kava } \\
\text { (Piper methysticum), usnic acid (usnea species) }\end{array}$ \\
\hline Mood alterations & $\begin{array}{l}\text { Anabolic steroids, belladonna (Atropa belladonna), ginseng (Panax ginseng), kra- } \\
\text { tom (Mitragyna speciosa), St. John's wort (Hypericum perforatum), yohimbe } \\
\text { (Pausinystalia yohimbe), stimulants†' }\end{array}$ \\
\hline Myocardial infarction & Ephedra (ephedra species), sibutramine \\
\hline Nausea, vomiting, diarrhea, anorexia & $\begin{array}{l}\text { Cholinesterase inhibitors (e.g., galantamine and huperzine A), echinacea (echina- } \\
\text { cea species), fenugreek (Trigonella foenum-graecum), guggul (Commiphora } \\
\text { wightii), hawthorn (crataegus species), horny goat weed (epimedium species), } \\
\text { neem (Azadirachta indica), oleander ( } N \text {. oleander), SAMe, saw palmetto } \\
\text { (Serenoa repens); see also hepatotoxic effects }\end{array}$ \\
\hline Nephrolithiasis & Calcium \\
\hline Osteoporotic fractures & Vitamin A \\
\hline $\begin{array}{l}\text { Palpitations, chest pain, tremor, anxiety } \\
\text { or panic attack, hypertension }\end{array}$ & $\begin{array}{l}\text { Ginseng ( } P \text {. ginseng), hawthorn (crataegus species), sibutramine, thyroid hor- } \\
\text { mones, yohimbe (P. yohimbe), stimulants (often combined with caffeine) } \uparrow\end{array}$ \\
\hline Rash and allergic reactions & $\begin{array}{l}\text { Bishop's weed (Ammi majus), chrysanthemum (Chrysanthemum morifolium), echi- } \\
\text { nacea (echinacea species), English ivy (Hedera helix), fenugreek (T. foenum- } \\
\text { graecum), guggul (C. wightii), NSAIDs, St. John's wort (H. perforatum), willow } \\
\text { bark (salix species) }\end{array}$ \\
\hline Stroke & DMAA, ephedra (ephedra species), ginkgo (G. biloba), sibutramine, stimulants $\dagger$ \\
\hline Visual changes or hypotension & Phosphodiesterase inhibitors (e.g., sildenafil and $>45$ new analogues) \\
\hline
\end{tabular}

* Catherine Ulbricht and Philip Gregory provided input on the table. DHEA denotes dehydroepiandrosterone, DMAA 1,3-dimethylamylamine, NSAIDs nonsteroidal antiinflammatory drugs, and SAMe S-adenosylmethionine.

$\dagger$ Examples of stimulants found in dietary supplements include DMAA, ephedra (ephedra species), $\beta$-methylphenethylamine

(MePEA), $N$, $\alpha$-diethyl-phenylethylamine (DEPEA), $N$-caffeoyldopamine, and $N$-coumaroyldopamine.

events with the FDA in real time. A supplement response team could be created, made up of expert clinicians, toxicologists, pharmacologists, and chemists. The team could be based at the $\mathrm{CDC}$, the FDA, the poison centers, or an academic institution. When consumers or physicians report a serious adverse event, the supplement response team could be alerted immediately. The multidisciplinary team could then offer clinical advice to physicians as they cared for patients, provide detailed reports to the FDA, and analyze patients' unused supplements for labeled and unlabeled ingredients. Supplement manufacturers could be required to provide complete manufacturing details and additional samples as requested. These changes would ensure not only that the FDA received accurate and timely reports, but also that clinicians received expert clinical advice as they cared for affected patients.

A pilot project incorporating several of these principles has already shown that active surveillance of poison-center reports can result in rapid identification of potentially harmful products. ${ }^{5}$ This successful pilot was terminated, however, because of a lack of funding. With more than half of U.S. adults taking supplements every year, at a cost of billions of dollars, consumers deserve a well-funded surveillance program capable of rapidly detecting hazardous supplements.

But even these ambitious changes would not prevent dangerous supplements from reaching consumers. If consumers and physicians are to have confidence that all supplements are safe, the law regulating supplements must be reformed. Every supplement ingredient should undergo rigorous safety testing before marketing. Until that happens, consumers and physicians cannot be assured that the pills, powders, and potions labeled as dietary supple- 
ments are safe for human consumption.

Disclosure forms provided by the author are available with the full text of this article at NEJM.org.

From the Cambridge Health Alliance, Somerville, MA; and Harvard Medical School, Boston.

1. Acute hepatitis and liver failure following the use of a dietary supplement intended for weight loss or muscle building - MayOctober 2013. MMWR Morb Mortal Wkly Rep 2013;62:817-9.

2. Tainted supplements CDER. Silver Spring, MD: Food and Drug Administration (http://www.accessdata.fda.gov/scripts/sda/ sdNavigation.cfm?filter $=\&$ sortColumn $=1 d$ $\&$ sd=tainted_supplements_cder\&page $=1$ ). 3. Cohen PA, Travis JC, Venhuis BJ. A methamphetamine analog ( $N, \alpha$-diethyl-phenylethylamine) identified in a mainstream dietary supplement. Drug Test Anal 2013 October 14 (Epub ahead of print).
4. Pawar RS, Grundel E, Fardin-Kia AR, Rader JI. Determination of selected biogenic amines in Acacia rigidula plant materials and dietary supplements using LC-MS/MS methods. J Pharm Biomed Anal 2014;88: 457-66.

5. Haller CA, Kearney T, Bent S, Ko R, Benowitz NL, Olson K. Dietary supplement adverse events: report of a one-year poison center surveillance project. J Med Toxicol 2008;4:84-92.

DOI: 10.1056/NEJMp1315559

Copyright @) 2014 Massachusetts Medical Society.

\section{Promoting Population Health through Financial Stewardship}

Peter A. Ubel, M.D., and Reshma Jagsi, M.D., D.Phil.

$\mathrm{H}$ ealth care costs are straining budgets throughout the developed world, threatening the fiscal solvency of governments, employers, and individuals. Many countries are trying to restrain health care spending through top-down approaches, such as price regulation and even refusal to reimburse for interventions that are not cost-effective. Still controversial is the role that physicians should play in controlling health care costs. For instance, the Choosing Wisely campaign of the American Board of Internal Medicine Foundation encourages physicians to avoid interventions that "may be unnecessary, and in some instances can cause harm," but it does not ask physicians to contemplate trading off small clinical benefits for individual patients in order to promote more general societal welfare. ${ }^{1}$

Yet concern for societal interests has long been recognized as part of physicians' duties. Physicians' specialized knowledge and skills result from publicly funded graduate medical education and the hands-on learning afforded to them by patients who allow trainees to participate in their care. In turn, physicians gain an obligation, as members of a uniquely privileged profession, to serve not only their individual patients but also society.

Consider the campaign launched by the Centers for Disease Control and Prevention to promote "antibiotic stewardship." The campaign recognizes that aggressive use of antibiotics in patients who are unlikely to benefit from their use promotes the development of antibiotic resistance, a serious public health problem. Thus, a physician who believes that an individual patient has only a small chance of benefiting from an antibiotic might choose not to prescribe one, out of a desire to forestall resistance in the population at large. Such societal stewardship involves forgoing a small, or even uncertain, benefit for an individual patient in order to promote the health and well-being of the general population.

Like antibiotic stewardship, financial stewardship can also promote the health and wellbeing of the population. It can promote patient health directly by benefiting the individual patients who receive less costly care (e.g., high out-of-pocket costs have been shown to be a leading cause of medication nonadherence). ${ }^{2}$ In addition, the burden of paying for medical care can cause more distress for patients than do many physiological side effects of treatment.

Financial stewardship also promotes population health by increasing people's access to affordable medical care. When health care costs rise, so do health insurance premiums, thereby pricing some employers and individuals out of the market. High health care costs have also influenced many state Medicaid programs to lower the maximum income for eligibility and have contributed to the unwillingness of some states to expand their Medicaid programs under the Affordable Care Act. The result is that many people have difficulty gaining access to affordable medical care, which ultimately harms health. Studies show that people with less insurance coverage have worse health outcomes. ${ }^{3}$ When physicians fail to act as financial stewards, they indirectly harm 